\title{
A Method for Evaluating Local Scour Depth at Bridge Piers due to Debris Accumulation
}

\author{
*Mohsen Ebrahimi, PhD, GMICE \\ Hydraulic Engineer, Mott MacDonald, Cambridge, CB1 2JD, UK; former Research Fellow at Centre for Water Systems, Univ. of Exeter \\ (corresponding author). E-mail: Mohsen.Ebrahimi@mottmac.com, ORCID number 0000-0003-3406-5526 \\ Slobodan Djordjević, PhD \\ Professor, Centre for Water Systems, University of Exeter, Exeter, U.K. \\ Diego Panici, PhD \\ Postdoctoral Research Associate. College of Engineering, Mathematics and Physical Sciences, University of Exeter, Exeter, U.K. \\ Gavin Tabor, PhD \\ Professor, College of Engineering, Mathematics and Physical Sciences, University of Exeter, Exeter, U.K. \\ Prakash Kripakaran, PhD \\ Senior Lecturer, College of Engineering, Mathematics and Physical Sciences, University of Exeter, Exeter, U.K
}

Abstract. This paper introduces a novel method for evaluating the effect of debris accumulation on local scour depth at bridge piers. The concept of a debris factor is proposed to replace the current effective and equivalent pier width approaches that have been shown to overestimate debris-induced scour in many instances. The concept enables a simpler, more direct and realistic estimation of the change in local scour depth due to debris since it accounts for (i) debris length (streamwise), width (spanwise) and thickness (depth wise), and (ii) the influence of debris elevation in flow, i.e. is applicable for free-surface debris, submerged debris, or debris resting on the stream bed. The concept works with all existing local scour equations alongside other factors that influence scour depth such as flow angle of attack and pier shape. The mathematical model that underpins the proposed concept is derived through multiple linear regression on experimental data obtained at Exeter and elsewhere. The proposed method is shown to improve accuracy by at least $24 \%$ and $5 \%$ in comparison to the effective and equivalent pier width approaches, respectively. More importantly, the method is shown to be robust, providing highly consistent results with significantly less uncertainty.

Author keywords: Bridges; Failure; River engineering; Hydraulics \& hydrodynamics; Railway tracks; Shallow foundations; Debris factor; Local scour; Bridge pier; Debris accumulation; Multiple linear regression. 


\section{Introduction}

Debris accumulation is widely recognized as a factor increasing scour risk at bridges (e.g. Chang and Shen 1979, Diehl 1997, Parola et al. 2000, May et al. 2002, Bradley et al. 2005, Arneson et al. 2012 and Benn 2013). This is due to debris constricting flow and increasing pier width, and consequently increasing flow velocities around the pier and enhancing scour.

The first study on the effect of debris on scour at piers was carried out by Laursen and Toch (1956) who showed that debris deepened and largened scour holes at piers. This effect was later quantified by Melville and Dongol (1992). They proposed the use of an effective pier width in place of the original pier width in local scour equations to consider the scour effect of debris. The effective pier width, which is larger than the actual pier width, is estimated using debris width and thickness, pier width and flow depth. This approach is also recommended in the first and second editions of the UK CIRIA manual on scour at bridges (May et al. 2002 and Kirby et al. 2015). Upon further research, Lagasse et al. (2010) proposed a revised version of the effective pier width approach known as the equivalent pier width approach. Their approach accounted for the upstream length of debris, a factor ignored in the original method proposed by Melville and Dongol (1992), and this led to considerable improvement in the estimations of scour depth. However, despite the improvements, the approach by Lagasse et al. (2010), which appears to be less popular within industry standards for scour assessment outside the US, retains a number of the same limitations as the approach by Melville and Dongol (1992). These limitations are listed below.

1. Both approaches generally overestimate scour depth when compared against data from laboratory experiments but with varying degrees of conservativeness. Although conservatism in scour predictions can be warranted for design, a precise prediction will allow for building in a known level of conservativeness when designing protection works for existing piers and for identification of foundation depth for newly designed piers.

2. The approaches have been tested only against a specific local scour equation. The approach by Lagasse et al. (2010) was based on the CSU equation proposed by Richardson and Davies (2001) and the approach by Melville and Dongol (1992) was based on the local scour equation proposed by Melville and Sutherland (1988). Using these approaches with other local scour equations can lead to a gross overestimation of debris-induced scour.

3. The approaches are applicable only to the scenario of debris located just under the flow free surface. Although this is the worst case scenario with respect to scour depth as shown by Ebrahimi et al. (2018), debris, in reality, can also be fully submerged or be located on the stream bed.

4. Both approaches have been developed and validated using data obtained for only one experimental data set, without considering experimental data produced by other researchers. The present work combines available experimental data from three experimental sources which is the majority of all available data.

The current paper introduces a new concept, called "debris factor", for estimating the effect of debris on scour depth at bridge piers. Instead of considering debris effect on scour indirectly by increasing the pier width, the proposed concept evaluates directly the change in scour depth in the presence of debris. This novel method is shown to be more accurate and 
robust compared to the effective or equivalent pier width approach. Furthermore, the method will be applicable in conjunction with all commonly used scour equations, be comprehensive by considering debris elevation and be simple to use in engineering practice.

The equation for computing the debris factor is derived using multiple linear regression analysis on data from inhouse flume experiments (Ebrahimi et al. 2018) and other reliable experimental data available in literature (Melville and Dongol 1992 and Lagasse et al. 2010). To facilitate the application of the proposed debris factor method, families of charts are also provided to directly estimate the debris factor using debris dimensions and its elevation in water column.

\section{Local Scour Equations}

Available equations for estimating local scour depth at piers typically use factors accounting for flow and pier characteristics. For instance, the equation by Melville and Coleman (2000), also recommended in the UK CIRIA manual for scour (Kirby et al. 2015), is as follows.

$$
\frac{d_{s}}{D}=\Phi_{\text {shape }} \Phi_{\text {depth }} \Phi_{\text {velocity }} \Phi_{\text {angle }}
$$

where $d_{s}$ is scour depth, $D$ is pier width, and $\Phi_{\text {shape }}, \Phi_{\text {depth }}, \Phi_{\text {velocity }}$ and $\Phi_{\text {angle }}$ are factors accounting for the effects of pier shape and flow depth, velocity and angle of attack relative to the pier, respectively.

To account for the scour effect of debris accumulation at the pier, we propose to include an additional factor called debris factor $\Phi_{\text {debris }}$ within Eq. (1). The proposed factor is essentially the ratio of local scour depth with debris $\left(d_{s}\right)$ to local scour depth without debris $\left(d_{s, 0}\right)$. Therefore $\Phi_{\text {debris }}$ can, in principle, be used to scale the local scour depth predicted by any local scour equation that has been developed without considering debris effects, e.g. equations by Melville and Coleman (2000), Richardson and Davies (2001), Oliveto and Hager (2002) and Sheppard et al. (2014).

Developing a reliable method to compute $\Phi_{\text {debris }}$ requires identification of the determinant debris and flow parameters by considering data that cover a range of practical scenarios. In the following sections, the paper introduces the data sets that are chosen to derive the method for computing $\Phi_{\text {debris }}$, the process of identifying the key parameters that influence $\Phi_{\text {debris }}$ and the development of a method for computing $\Phi_{\text {debris }}$ that is based on the available experimental data.

\section{Data from Flume Experiments}

The method for computing $\Phi_{\text {debris }}$ is derived from experimental data available from three sources in literature - Ebrahimi et al. (2018), Lagasse et al. (2010) and Melville and Dongol (1992). Another available source of experimental data is the work of Pagliara and Carnacina (2011a). Their data have not been considered since their experiments used an exceptionally small flow width-to-depth ratio $(B / h \leq 3.6)$ in comparison to $B / h \simeq 4.3-15.2$ in experiments in other chosen studies. Importantly, 
the latter range of $B / h$ is also representative of the majority of natural rivers except those in very steep terrains according to Rosgen Stream Classification System (Rosgen 1985). Furthermore, this study also excludes or combines data corresponding to a few specific scenarios from the chosen three studies for the reasons outlined below.

1. While triangular-in-profile (in vertical direction) debris is a common scenario in reality (e.g. Wellwood and Fenwick 1990 and Diehl 1997), available experimental results for this type of debris are excluded due to (i) the relatively small number of experiments available and (ii) the distinct effect this debris geometry has on flow pattern, i.e. less severe flow deflection and higher flow shedding around debris, compared to that of rectangular debris (Lagasse et al. 2010 and Rahimi et al. 2018).

2. Data only from experiments in which the maximum scour depth is measured are used as this parameter is required to develop a method for computing $\Phi_{\text {debris }}$. Specifically data from four experiments by Lagasse et al. (2010) in which scour depth was measured away from the location of maximum scour depth (i.e. pier nose) are not used.

3. Effect of debris roughness and porosity are not considered in the proposed debris factor method since, as found by Pagliara and Carnacina (2010) and Lagasse et al. (2010), they do not affect depth and pattern of scour in any appreciable way and can only be considered secondary factors when compared with dimensions of debris and flow intensity. Therefore, experiments by Lagasse et al. (2010) that differed only in the porosity or debris roughness are grouped together into one experimental scenario with the scour depth taken as the average of the values obtained amongst the experiments. This process resulted in a total of five combined experimental scenarios of Lagasse et al. (2010) as shown in Table 1. The merging of experimental data is justified since the largest standard deviation of $d_{s} / d_{s, 0}$ in these five sets was relatively small at 0.1 .

4. Tests 004_04B and 007_01B by Lagasse et al. (2010) that were carried out with a long free-surface debris are excluded due to an anomaly observed in the data. Flow physics dictates that these tests should have resulted in scour depths larger than the corresponding baseline test, i.e. without debris. However, the final measured scour depths were less than that of the baseline test, which is physically unexplainable.

Experimental data from a total of 43 scenarios are available from the chosen three sources after performing the steps outlined above. Table 1 summarizes this data. Data are classified into three groups 1-3 according to their source. Data from a specific experiment is also given a reference that consists of an abbreviation of the lead author name of the source (ME, PL and BM) followed by a number that matches the test number used within the source. Due to the small number of datasets, all the groups 1-3 are used for training the proposed regression model to enhance the robustness of the model in predicting $\Phi_{\text {debris }}$.

In Table $1, B=$ flow width (= flume width); $h=$ depth of approach flow; $U=$ mean velocity of approach flow (= $Q /(B h)), U_{c r}=$ critical flow velocity for initiation of sediment movement; $D=$ pier width; $d_{50}=$ median particle size of sand bed; $L_{d}=$ streamwise length of debris (at upstream of the pier center); $W_{d}=$ spanwise length of debris; $T_{d}=$ submerged thickness 
of debris; $h_{d}=$ distance of bottom of debris to the initial bed; and $\Phi_{\text {debris }}=d_{s} / d_{s, 0}=$ the ratio of scour depth with debris to scour depth without debris, where $d_{s}=$ maximum measured scour depth (with debris) and $d_{s, 0}=$ maximum measured scour depth in the corresponding baseline (no debris) test with similar hydraulic conditions. Debris elevation refers to the position of debris in water column with FS indicating that debris is just below flow free surface. The flow angle of attack relative to the pier is zero in all experiments even though this scenario is rare in field conditions.

The following notable aspects are acknowledged about the experiments from which the chosen data have been obtained.

1. Experiments in groups 1 and 2 were carried out with log-shape and cuboidal debris located upstream of the pier, while experiments in group 3 featured an annulus-shaped debris (circular in plan) centered on the pier. For consistency in this study, the length of debris located upstream of the pier centre alone is taken as the streamwise length of the debris, $L_{d}$, even if debris was to extent downstream of the pier centre. This is reasonable since debris usually does not extend downstream in practice (see e.g. Lagasse et al. 2010). Also the downstream portion of debris is unlikely to affect the maximum scour depth which is usually located on the upstream side of the pier.

2. All the chosen experiments were carried out with relative particle sizes $D / d_{50}$ in the range $35-145$ which corresponds to non-cohesive coarse to medium sediment.

3. The duration of the scour experiments varied between the groups. As stated by Ebrahimi et al. (2018), the short duration of 5 hours in group 1 experiments is sufficient to reach quasi-equilibrium scour. Also, the range of $\Phi_{\text {debris }}$ values in group 3, which included experiments with significantly longer duration of 150 hours, is comparable with those in other groups. Moreover, in experiments performed by Lagasse et al. (2010) for short and long durations, no meaningful difference was observed in $\Phi_{\text {debris }}$. Therefore data from all the available experiments are used irrespective of their durations.

\section{Proposed Method}

An initial analysis of the data showed that the change in scour depth due to debris depends on debris dimensions $\left(L_{d}, W_{d}, T_{d}\right)$ and its elevation in water column $\left(h_{d}\right)$.

To make the final model simple, effect of $U / U_{c r}$, which is a measure of flow intensity, is neglected. This is justified by the fact that in the experiments by Lagasse et al. (2010), $U / U_{c r}$ did not appear to have a meaningful effect on $\Phi_{\text {debris }}$. In other words, for the experiments in group 2 with $U / U_{c r}=0.7$, the average $\Phi_{\text {debris }}$ was 1.24 , while for experiments with $U / U_{c r}$ $=1, \Phi_{\text {debris }}$ was 1.22 .

As shown by Melville and Dongol (1992), Lagasse et al. (2010) and Ebrahimi et al. (2018), flow depth $h$ and pier diameter $D$, have appreciable effect on the change of scour depth due to debris. Therefore, using Buckingham's $\pi$ Theorem, the following function can be written to explain the relationship between variables 
$f\left(\Phi_{\text {debris }}, L_{d}, W_{d}, T_{d}, h_{d}, D, B, h\right)=0$

Amongst the 8 independent variables, there is 1 primary dimension, i.e. [L]. Therefore, based on Buckingham's $\pi$ Theorem and using $h$ as the repeater variable, there are 7 dimensionless groups of $\pi$ 's relating the variables using following equation

$\pi_{1}=f\left(\pi_{2}, \pi_{3}, \pi_{4}, \pi_{5}, \pi_{6}, \pi_{7}\right)$

where $\pi_{1}=\Phi_{\text {debris }}, \pi_{2}=L_{d} / h, \pi_{3}=W_{d} / h, \pi_{4}=T_{d} / h, \pi_{5}=h_{d} / h, \pi_{6}=D / h, \pi_{7}=B / h$. Rearranging $\pi$ groups as $\pi_{2} / \pi_{6}$ and $\pi_{3} \pi_{4} / \pi_{7}$, results in the following equation.

$\Phi_{\text {debris }}=f\left(L_{d} / D, W_{d} T_{d} / B . h, h_{d} / h\right)$

Let $\Delta A=\frac{W_{d} T_{d}}{B . h} . \Delta A$ is effectively the percentage of the flow cross section blocked by debris. Therefore, Eq.

can be re-written as follows.

$\Phi_{\text {debris }}=\frac{d_{s}}{d_{s, 0}}=f\left(L_{d} / D, \Delta A, h_{d} / h\right)$

As shown in the following section, there is a functional relationship between $\Phi_{\text {debris }}$ and each of independent variables $L_{d} / D, \Delta A$ and $h_{d} / h$ which is shown by $K 1, K_{2}$ and $K 3$ ratios respectively. Each $K$, therefore, represents the effect of the corresponding independent variable on $\Phi_{\text {debris }}$ while other variables are held constant. $K$ ratios are derived using current literature and according to the available statistical evidence that is indicative of the influence of each of independent variables on $\Phi_{\text {debris }}$.

\section{$K_{1}$, effect of normalised debris length, $L_{d} / D$}

For free surface (FS) debris, three points can be identified, for relationship $\Phi_{\text {debris }}$ between and $L_{d} / D$, from the current literature and theory as described here. Point 1: Based on Pagliara and Carnacina (2011b), $\Phi_{\text {debris }} \simeq 2$ is assumed here for when streamwise length of debris is equal to $3 D$. This is close to the maximum value of $\Phi_{\text {debris }}=1.75$ proposed by de Almeida et al. (2018). It is also in agreement with findings by Lagasse et al. (2010) that maximum scour amplification occurs when $L_{d}$ $=h=3 D$. Point 2: For very long debris at free surface, Lagasse et al. (2010) showed that ratio of increase of scour approaches 1.5. Therefore, here it is assumed that when $L_{d} / D$ approaches infinity, there is always some finite increase in scour depth identified with $\Phi_{\text {debris }}=1.5$. Point 3: It is theoretically known that when $L_{d} / D=0, \Phi_{\text {debris }}=1$ meaning no scour increase. Accordingly, the variation of $\Phi_{\text {debris }}$ with $L_{d} / D$ for FS debris is assumed as shown in Fig. 1(a) with Eq. (6). 
FS debris:

$$
K_{1}=\frac{1.33\left(L_{d} / D\right)^{2}-2 L_{d} / D^{+6}}{\left(\frac{\left.L_{d} / D\right)^{2}-3 L_{d} / D+6}{D}\right.}
$$

For debris being located on bed, it is hypothesised that with increment of debris length, scour depth decreases so that when $L_{d} / D$ approaches infinity, $\Phi_{\text {debris }}$ approaches zero. This can be justified because in reality the longer the debris is, the higher the flow energy dissipation and the smaller the scour depth will be. It should be also emphasised that here the "effect of debris" refers to the localised effect of debris on changing scour depth and not the finite scour that can always happen immediately downstream of debris at the pier. In this regard, it is expected that the longer the debris is, the smaller the scour hole under it will be. This bed protecting effect of debris is similar to findings by Ebrahimi et al. (2018), Rahimi et al. (2018) and Dias et al. (2019). Therefore, it is assumed that variation of $\Phi_{\text {debris }}$ with $L_{d} / D$ for on-bed debris is as shown in Fig. 1(b) and Eq. (7).

Debris on bed: $\quad K_{1}=\frac{0.95}{\left(L_{d} / D\right)^{2.5}+1}+0.05$

In Fig. 1, the curvature of curves at $L_{d} / D=0$ is defined so that $d\left(\Phi_{\text {debris }}\right) / d\left(L_{d} / D\right)=0$.

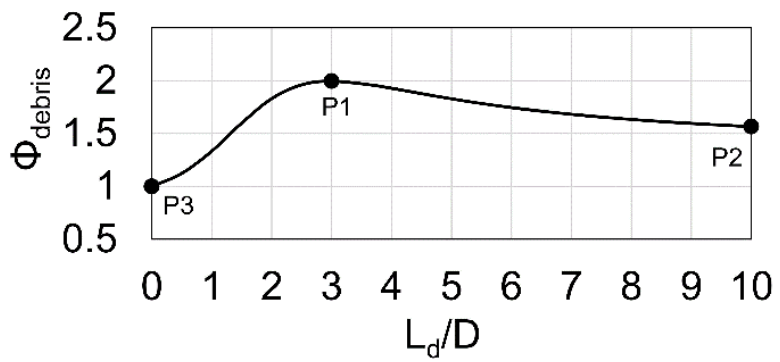

(a)

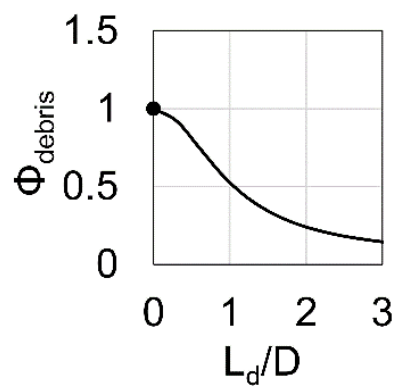

(b)

Fig. 1. Effect of normalized debris length $\left(L_{d} / D\right)$ on $\Phi_{\text {debris }}$ : (a) debris at free surface; (b) debris on bed. Solid dots are the available benchmark points as described in section " $K_{1}$, effect of normalised debris length, $L_{d} / D$ ". 
For submerged debris, Ebrahimi et al. (2018) found that scour depth is between the scour depth for free-surface and on-bed debris. Therefore, an intermediate equation between Eq. (5) and (6) is expected to explain the relationship between $\Phi_{\text {debris }}$ and $L_{d} / D$. In the chosen data set, there are only two experiments with submerged debris and identical debris dimensions and hydraulic conditions (ME3 and ME4). Therefore, due to not having sufficient data from experiments with submerged debris, the following assumption is made.

Submerged debris: $\quad K_{1}=1$

\section{$K_{2}$, effect of blockage percentage, $\Delta A$}

Blockage percentage, $\Delta A$, is the combined effect of debris width $W_{d}$ and thickness $T_{d}$. Melville and Dongol (1992), Lagasse et al. (2010) and Pagliara and Carnacina (2011a) showed that scour depth depends highly on debris width multiplied by debris thickness. To illustrate the relationship between $\Phi_{\text {debris }}$ and $\Delta A$, all the named experiments of groups 1-3 which had identical hydraulic conditions, $L_{d} / D$, and debris elevation are grouped together. Groups that have at least two datapoints are plotted in Fig. 2.

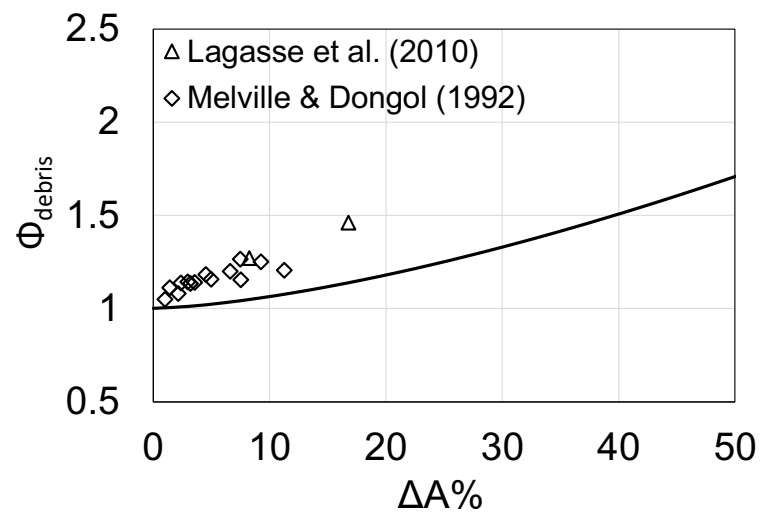

Fig. 2. Effect of blockage percentage, $\Delta A$, on $\Phi_{\text {debris }}$ in experiment by various authors.

The following equation, with the general form adopted from Pagliara and Carnacina (2011), is fitted to the data in Fig. 2.

$$
K_{2}=1+0.002 \Delta A^{1.5}
$$

where $\Delta A=\frac{W_{d} T_{d}}{B . h} \times 100$

The proposed curve in Fig. 2, while not a perfect fit to the data, does largely conform to observations, specifically in two aspects: 1) As $\Delta A$ becomes larger, debris thickness increases, i.e. the bottom of debris gets closer to the bed. As shown by Ebrahimi et al. (2018), this has some protecting effect on the bed which reduces the increasing rate of $\Phi_{\text {debris }}$; therefore a smaller-power relationship is envisaged to be more representative for the relationship between $\Phi_{\text {debris }}$ and $\Delta A$; 2) Based on reported data in literature, when $\Delta A$ approaches $50 \%, \Phi_{\text {debris }}$ approaches $\sim 2$. 


\section{$K_{3}$, effect of normalised debris elevation in water column, $h_{d} / h$}

Ebrahimi et al. (2018), using five experiments with debris fixed at different elevations (Scenario 1 in the original source and ME2-5) - namely FS, submerged and on-bed debris, derived the relationship between $\Phi_{\text {debris }}$ and $h_{d} / h$. The corresponding data points are illustrated in Fig. 3 with the following polynomial equation proposed to fit the data.

$$
K_{3}=-0.76\left(h_{d} / h\right)^{3}+0.6\left(h_{d} / h\right)^{2}+0.28\left(h_{d} / h\right)+0.88
$$

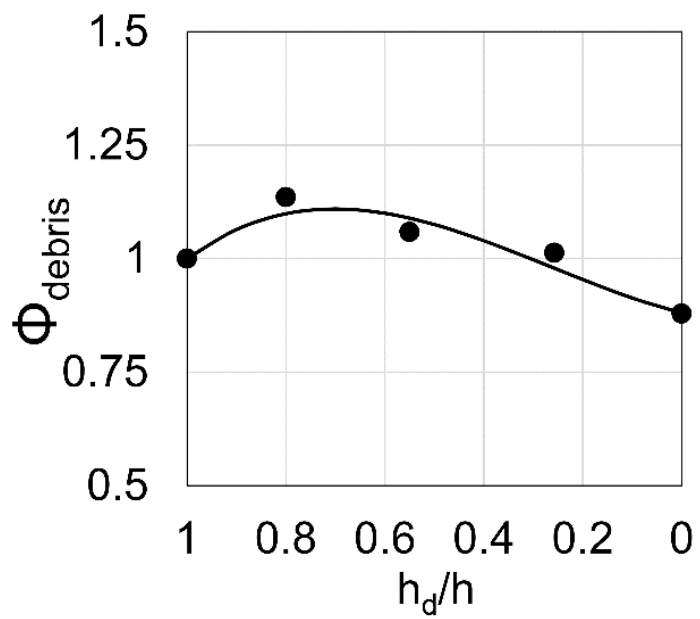

Fig. 3. Effect of normalized debris elevation, $h_{d} / h$ on $\Phi_{\text {debris }}$ in scenarios $1-5$ by Ebrahimi et al. (2018).

\section{Training (Multiple Linear Regression)}

Results from experiments in literature (e.g. Lagasse et al. 2010 and Ebrahimi et al. 2018) show that scour depth increase is related neither linearly nor proportionately with debris characteristics. For example, consider two scenarios. Scenario S1 has a debris that is 2 times wider and 3 times longer than the debris in scenario S2. This does not imply that the scour depth increase in S1 is $6(=2 \times 3)$ times the scour depth increase in S2. Also, neither is the scour depth increase in S1 obtained by multiplying $K_{1}, K_{2}$ and $K_{3}$ separately based on debris characteristics, i.e. a product of the $K$-ratios does not provide a reliable estimate of $\Phi_{\text {debris }}$. To model the relationship between the response variable $\Phi_{\text {debris }}$ and explanatory (predictor) variables of $K_{1}-K_{3}$, a multiple linear regression analysis is therefore carried out using the data in Table 1. To do this, following equation is adopted to show the relationship between $\Phi_{\text {debris }}$ and $K$ ratios.

$\Phi_{\text {debris }}=K_{1}^{\theta_{1}} \cdot K_{2}^{\theta_{2}} \cdot K_{3}^{\theta_{3}}$

where $\theta_{1}$ to $\theta_{3}$ are the exponents to be found via regression analysis.

A multiple linear regression model is trained using datapoints in groups 1-3 in Table 1 to investigate the statistical relationship between the response variable ( $\left.\Phi_{\text {debris }}\right)$ and explanatory variables $\left(K_{1}\right.$ to $K_{3}$.). Due to the small size of dataset, i.e. 43 datapoints, all the data is used to train the regression model to enhance the robustness of the proposed concept. 
In order to enable doing a multiple linear regression analysis, a dummy coefficient $\left(e^{\theta_{0}}\right.$ with $\left.\theta_{0}=0\right)$ is applied to Eq. (11) as following

$\Phi_{\text {debris }}=e^{\theta_{0}} \cdot K_{1}^{\theta_{1}} \cdot K_{2}^{\theta_{2}} \cdot K_{3}^{\theta_{3}} \quad ; \quad \theta_{0}=0$

Applying natural logarithm on both sides of Eq. (12) gives

$\ln \left(\Phi_{\text {debris }}\right)=\theta_{0} \times 1+\theta_{1} \times \ln K_{1}+\theta_{2} \times \ln K_{2}+\theta_{3} \times \ln K_{3}$

Substituting data for each scenario within the training set will result in 43 linear simultaneous equations as given below in matrix notation.

$\left(\begin{array}{c}\ln \Phi_{\text {debris }, 1} \\ \vdots \\ \ln \Phi_{\text {debris }, 43}\end{array}\right)=\left[\begin{array}{cccc}1 & \ln K_{1,1} & \ln K_{1,2} & \ln K_{1,3} \\ & & \vdots & \\ 1 & \ln K_{43,1} & \ln K_{43,2} & \ln K_{43,3}\end{array}\right]\left\{\begin{array}{l}\theta_{0} \\ \theta_{1} \\ \theta_{2} \\ \theta_{3}\end{array}\right\}=[K]\{\theta\}$

$\theta$ can be computed as

$\{\theta\}=\left([K]^{T}[K]\right)^{-1}[K]^{T}\left(\Phi_{\text {debris }}\right)$

which gives

$\theta_{1}=0.24, \theta_{2}=0.6, \theta_{3}=0.25$

Therefore, from Eq. (11),

$\Phi_{\text {debris }}=K_{1}^{0.24} \cdot K_{2}^{0.6} \cdot K_{3}^{0.25}$

Fig. 4 shows a comparison between the predicted and measured $\Phi_{\text {debris }}$ values for the chosen dataset. The coefficient of determination is $R^{2}=72 \%$. This shows a relatively small variance between the predicted and observed values which considering the small number of the training samples and their experimental nature is acceptable. The largest variation is for two scenarios above the diagonal line from Group 2, i.e. scenarios PL004_04C, 007_01D and PL004_04A. This is discussed in section "Discussion". 


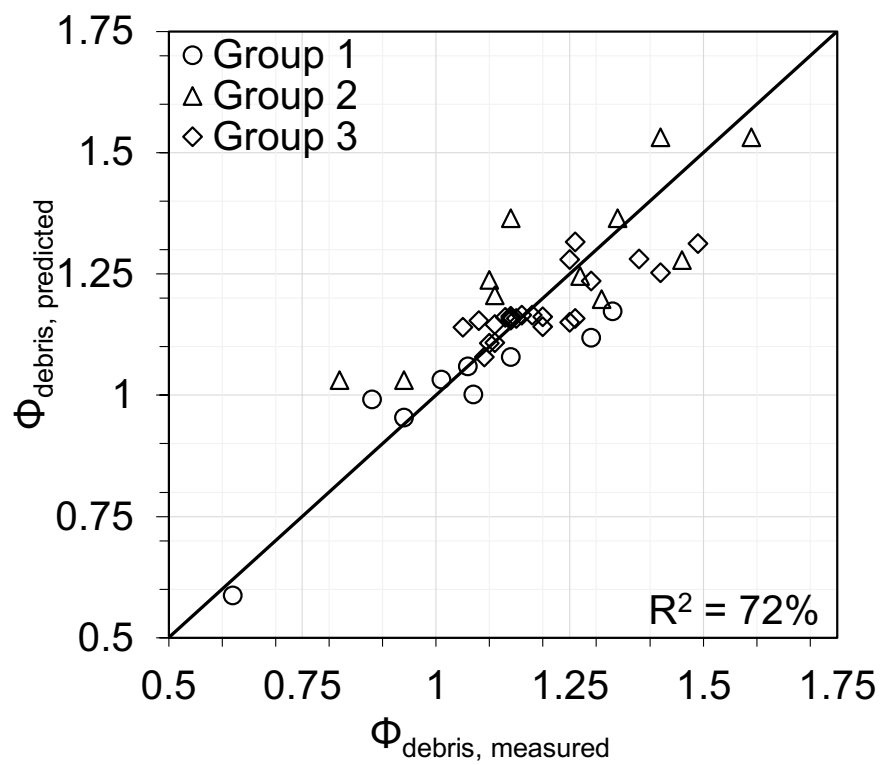

Fig. 4. Comparison of $\Phi_{\text {debris }}$ predicted by the proposed concept and chosen experimental data.

More important than the goodness of the fit is the reliability of the predictions by the proposed concept. In order to demonstrate that predictions are not biased, residuals and their probability density are illustrated in Fig. 5. Residual for each datapoint is calculated as $\Phi_{\text {debris,measured }}-\Phi_{\text {debris,predicted }}$. As can be seen the residuals are fairly evenly distributed around zero, meaning non-biased predictions. However, a tendency of under-prediction (positive residual) for larger measured $\Phi_{\text {debris }}$ values can be observed. In addition, the probability density of residuals shown in Fig. 5(b) is approximately symmetrical which is right-skewed only by $\sim 0.0125$. This small right skewness of the probability density curve shows the small degree of underestimation by the proposed concept. It can be however seen that the residuals can be as high as about 0.18 which shows the highest degree of underestimation.

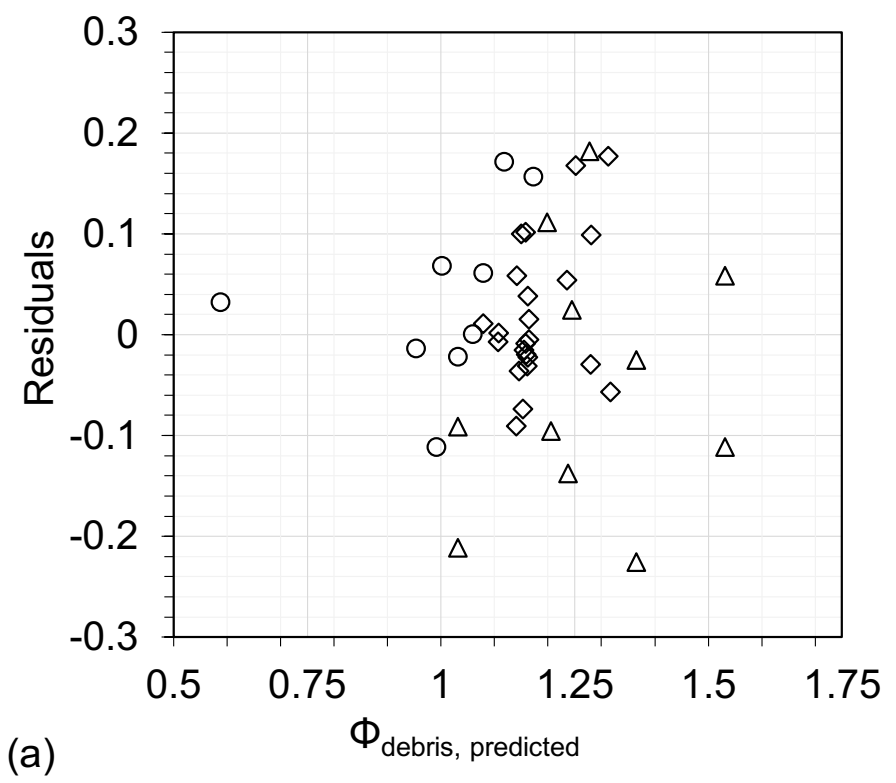




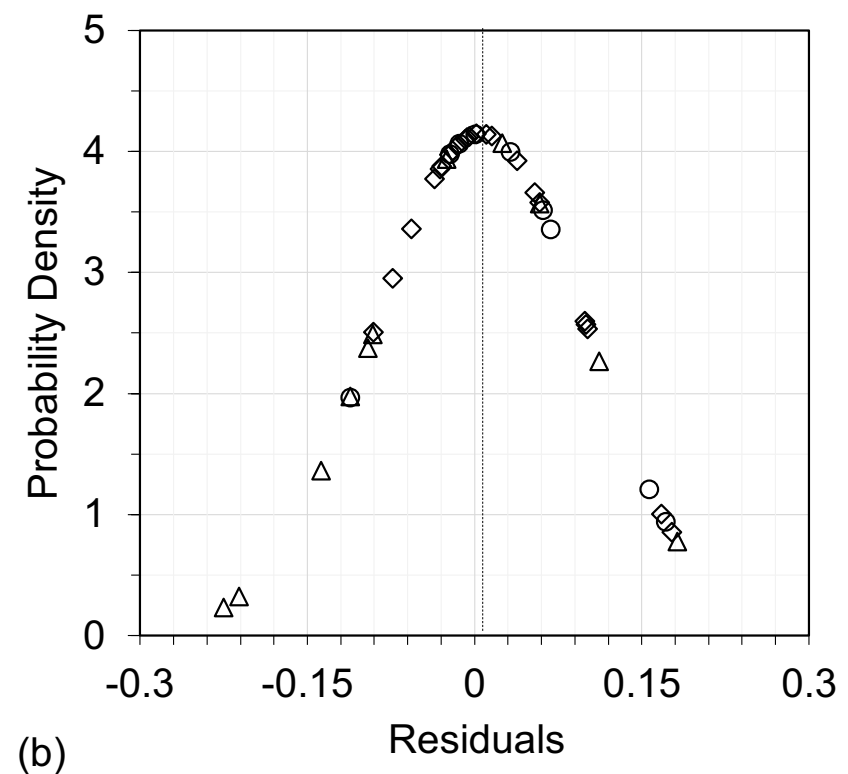

Fig. 5. Residuals of prediction by the proposed concept (a) and their probability density (b). Data from Groups 1,2 and 3 are shown by circle, triangle and diamond symbols, respectively.

Fig. 6 compares the predictions with existing empirical approaches - namely, the effective pier width approach by Melville and Dongol (1992) and the equivalent pier width approach by Lagasse et al. (2010). These two approaches are applicable only to debris at free surface. Therefore the comparison is only carried out for the experiments with FS debris, i.e. excluding nine of the scenarios in groups 1-3. To evaluate the performance of the empirical approaches a scour-estimating equation is required in which the effective/equivalent pier width is utilized instead of the actual pier width. An analysis of the widely-used local scour equations (Ebrahimi et al. 2018) showed that the above two empirical approaches work best with CSU equation proposed by Richardson and Davies (2001). This equation is adopted here. As can be seen in Fig. 6, the proposed concept estimates the measured $\Phi_{\text {debris }}$ with much better accuracy. The mean absolute difference of the predictions from observations in the proposed concept is 5.4\% while the approaches by Melville and Dongol (1992) and Lagasse et al. (2010) show and average of $30 \%$ and $11 \%$ difference from the observed values, respectively. The $24.6 \%$ reduction in difference from observations by the proposed method compared to the commonly-used approach of effective pier width is significant. Although Lagasse et al. (2010) have improved the latter approach considerably, the further 5.6\% reduction by the proposed method is important. More importantly and as can be seen in Fig. 6,

1) the above two approaches estimate $\Phi_{\text {debris }}$ with high levels of uncertainty particularly when $\Phi_{\text {debris }}$ is large, while the predictions by the proposed method is more consistently spread around the prefect-fit line.

2) using other local scour equations with the effective or equivalent pier width approach can lead to a much larger overestimation of local scour depth. For example, the effective and equivalent pier width approaches when used with Melville and Coleman (2000) equation result in $47 \%$ and $25.5 \%$ overestimation, respectively. 


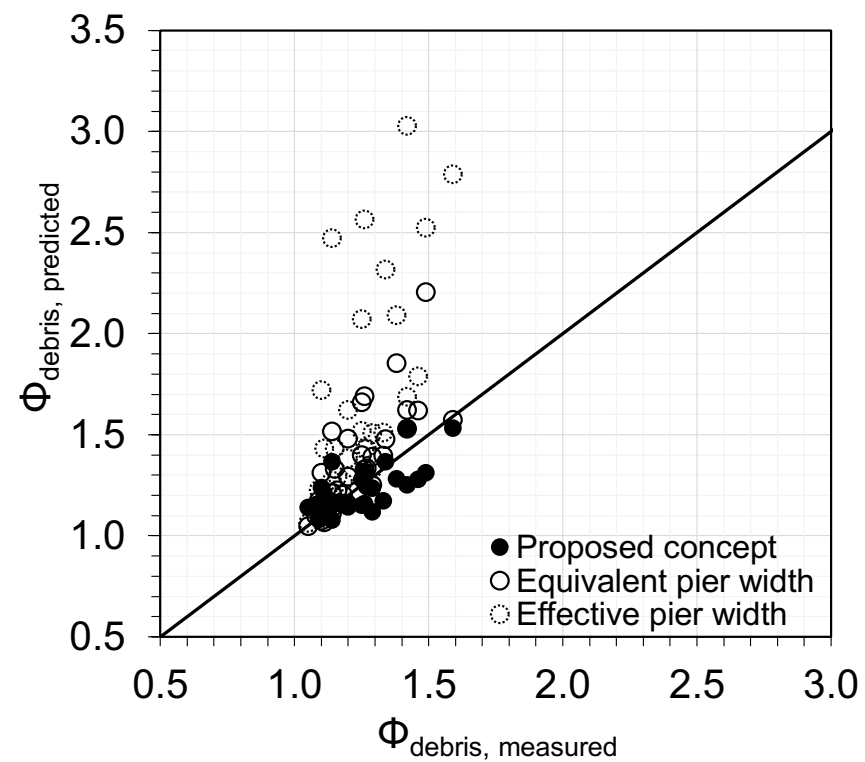

Fig. 6. Comparison of $\Phi_{\text {debris }}$ predicted by the proposed concept with the "best" estimate by existing empirical approaches for debris at free surface.

Lastly, it should be emphasised that the proposed approach is derived solely from experiments with particular debris geometry. Site data in prototype scale can suggest larger scour increase due to large flat debris. Therefore, it is envisaged that characterising debris geometry of potential accumulations is critical, and it is advised to test the proposed debris factor with debris geometry other than those considered here.

\section{Application Procedure}

Application of the proposed method requires using Eqn. (16) and Eqns. 6-10. While this can be programmed into a spreadsheet or a similar tool, a simpler approach is to present the equations in the form of charts. Sample charts are presented in Fig. 7 and Fig. 8 for the cases of FS debris and on-bed debris.

When debris is blocking the entire flow depth, i.e. $T_{d} / h$ is approaching 1 , finding $\Phi_{\text {debris }}$ requires some judgment. In this case, if debris is a floating object growing from the flow free surface toward the bed, Fig. 7 should be used. However, if debris has been resting on the bed and growing from the bed toward the free surface, Fig. 8 should be used. 

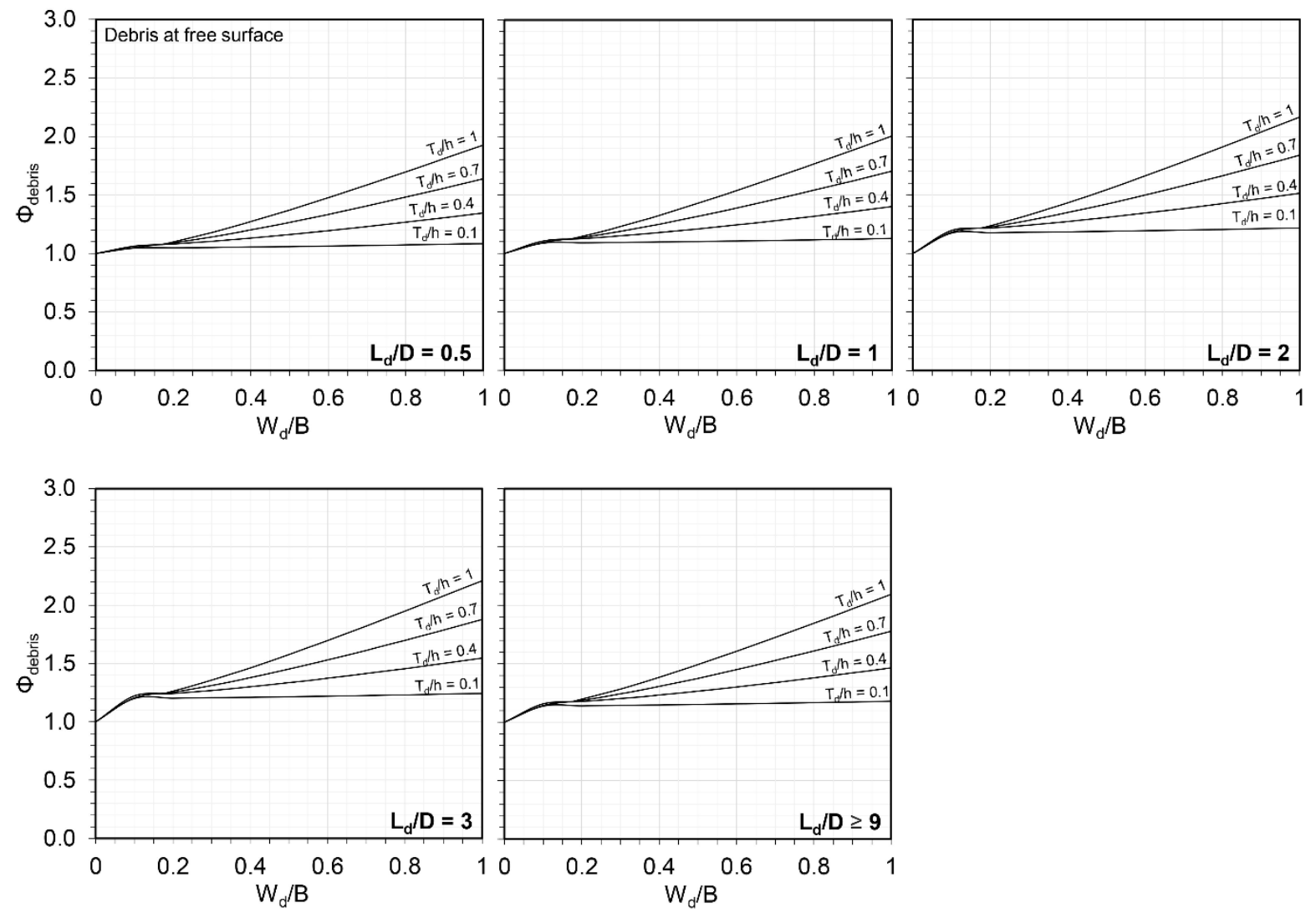

Fig. 7. Family of charts for estimating $\Phi_{\text {debris }}$ from normalized debris dimensions for FS debris.
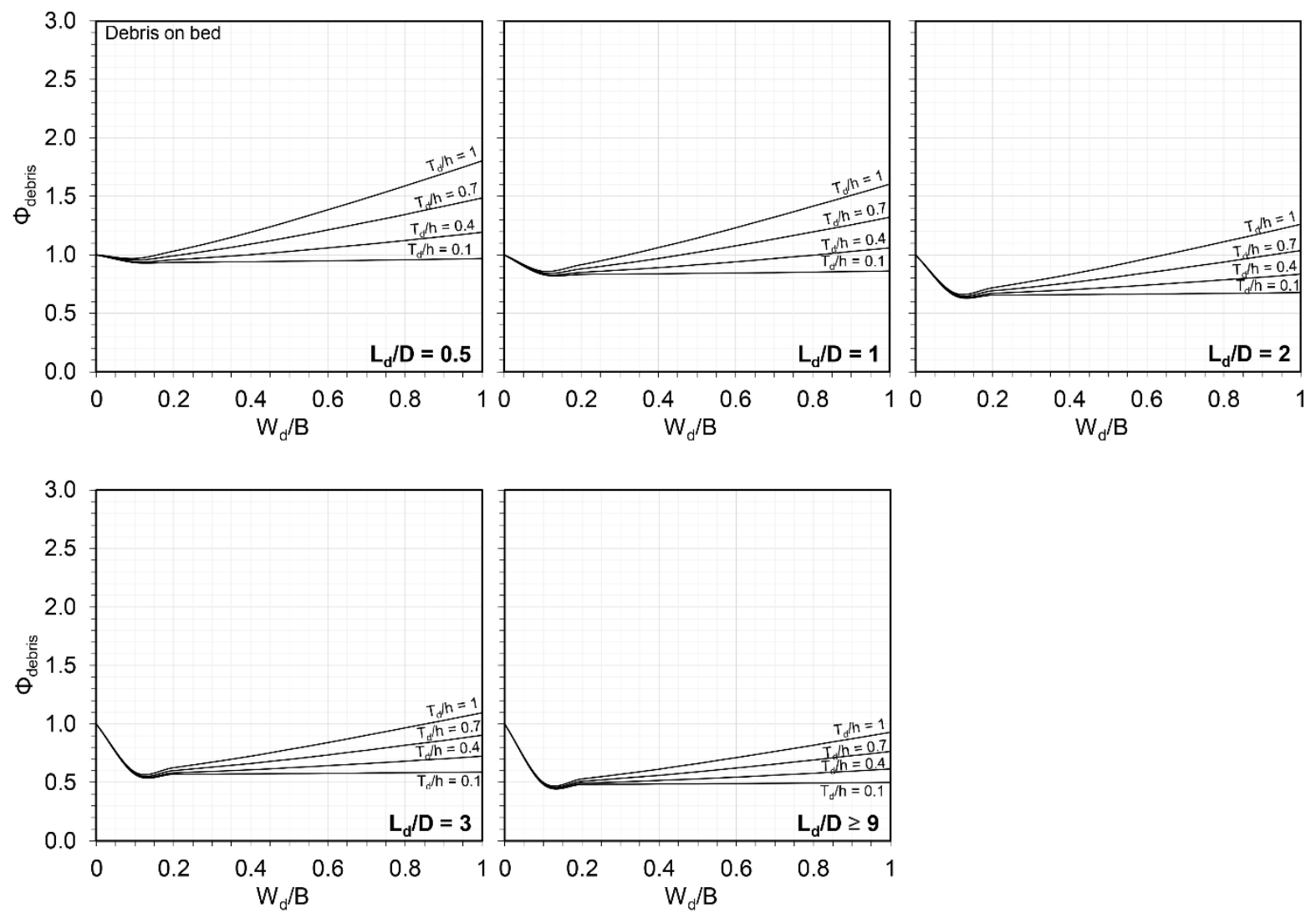

Fig. 8. Family of charts for estimating $\Phi_{\text {debris }}$ from normalized debris dimensions for on-bed debris. 


\section{Real-World Example: Feltham Incident}

This section illustrates the application of the proposed debris factor to a real-world bridge - Bridge RDG1 48 near Feltham in the UK. It was a Victorian single-span arch built in 1848 and located between Feltham and Feltham Junction. It is acknowledged that the proposed concept is developed for and based on data from single bridge piers, and the flow structure at an abutment can be different from that of a pier. The chosen example is however presented not to discuss scour mechanism at the bridge abutment, but solely to show the effect of debris on local scour depth and application of the proposed concept. This is also justified by the fact that UK Design Manual for Roads and Bridges (DMRB BD97/12) recommends pier scour method for abutment scour estimation.

Bridge RDG1 48 carried rail traffic that was part of the Wessex route over the River Crane having flow direction as shown in Fig. 9 The bridge failed on 14 Nov 2009 due to subsidence of the east side of the bridge caused by scour at the east abutment (left abutment when looking downstream). This resulted in differential settlement, twist in the brick arch and serious defect to the structure. The dislocation of arch at upstream face also caused loss of ballast beneath six of the railway track sleepers in the up (towards London) line (RAIB 2010). Upon the reports by train drivers about feeling a dip in the track, the line was blocked and further site investigations were carried out. The bridge was subsequently demolished and rebuilt as a reinforced concrete structure.

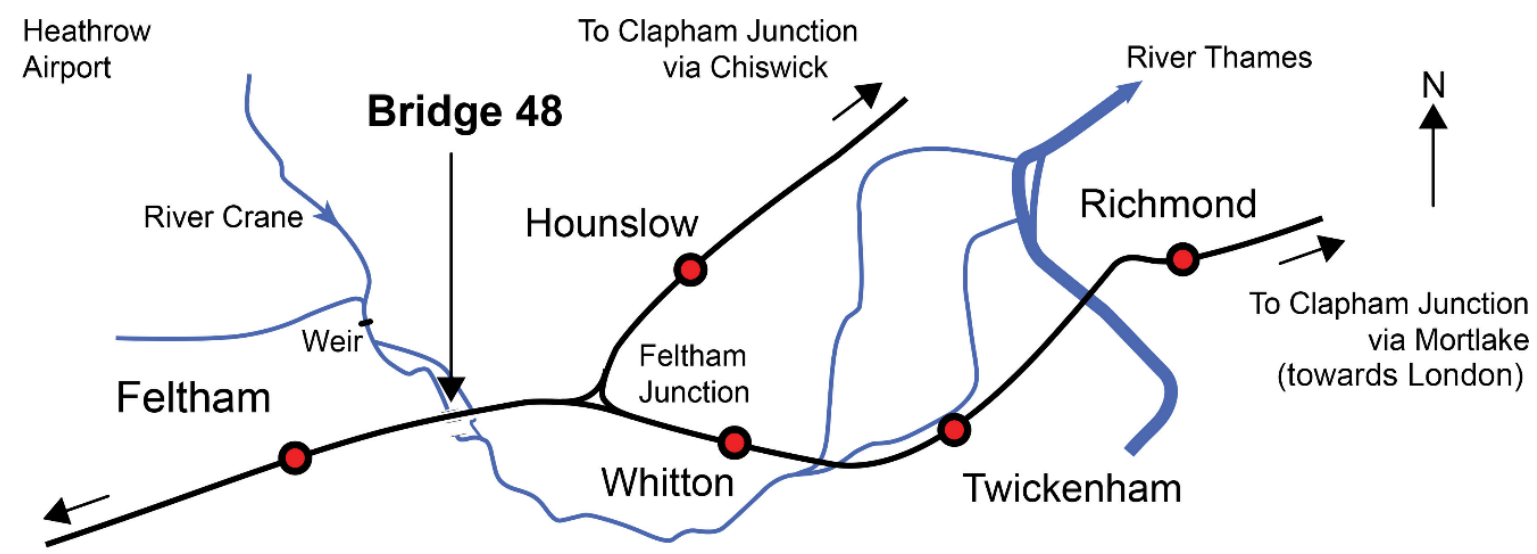

To Windsor Reading and Weybridge via Staines

Fig. 9. Location of Bridge RDG1 48 (RAIB 2010).

A schematic of the bridge is shown in Fig. 10. Structural dimensions are extracted from historical drawings provided by Network Rail and from data in RAIB (2010). Flow depth $h=0.4 \mathrm{~m}$ is estimated from the river slope $=0.0019$, bed particle size $d_{50}=20 \mathrm{~mm}$ (obtained via private communication) and peak flow rate $=3.09 \mathrm{~m}^{3} / \mathrm{s}$ measured at an upstream gauging station (RAIB 2010). The bridge span was $6.1 \mathrm{~m}$ and the bridge length (in the direction normal to the span) was $8.46 \mathrm{~m}$. In 1858 , foundation of the right (west) abutment was deepened to 1.5 meters below bed level, while the left (east) abutment being $0.4 \mathrm{~m}$ wide retained its original foundation depth of only $d_{f}=0.65 \mathrm{~m}$ without any scour protection. It should be emphasised 

characteristic width. Therefore, here $D=0.48 \mathrm{~m}$.

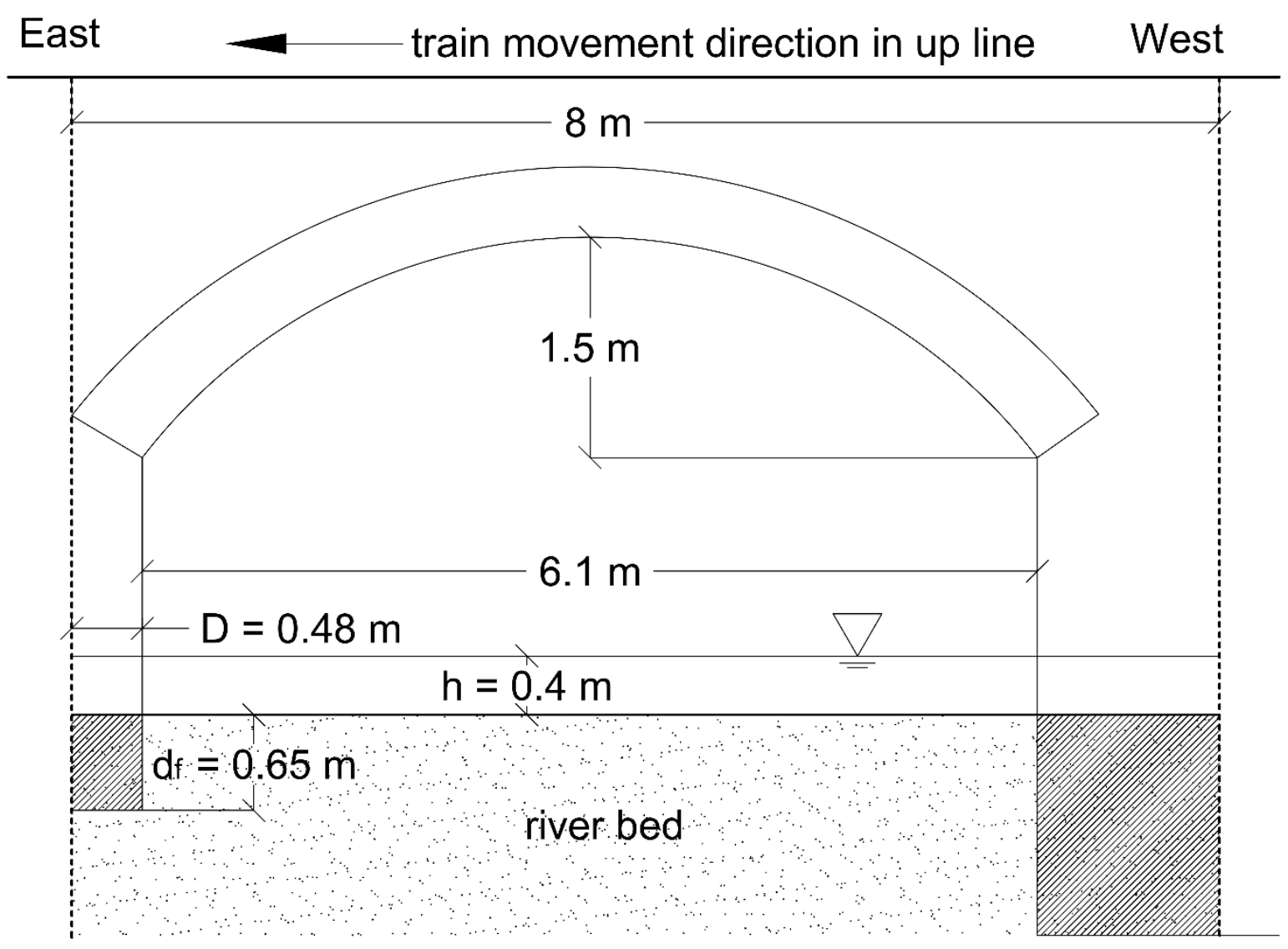

Fig. 10. Cross-sectional schematic of Bridge RDG1 48 (looking downstream). Hatched zones show the depth of foundations. Length of the bridge (in direction normal to the span) was $8.46 \mathrm{~m}$. Only the bridge span, between two dashed verticals, relevant to the incident is shown for simplicity.

Here the proposed method for estimating $\Phi_{\text {debris }}$ is illustrated for the east abutment. Although the proposed method is originally developed for bridge piers, it may be applied to an abutment by choosing the appropriate span length $B$. For this case, $B=3.05 \mathrm{~m}$. A photo of debris accumulation, adopted from RAIB (2010) and shown in Fig. 11, is used to roughly estimate debris dimensions. The normalized debris length $L_{d} / D$ is assumed to be 0.5 . Although debris appeared to be blocking the entire depth of the shallow flow, normalized debris thickness $T_{d} / h$ is assumed to be $\sim 0.5$. This value is chosen to show the potential scour effect of debris even when debris thickness is highly underestimated. $W_{d} / B$ is assumed to be 1 , where $B$ is the span length corresponding to the east abutment assumed to be half of the bridge span (although the bridge is located on a $10^{\circ}$ bend). From Fig. 11, debris would appear to be located at the flow free surface; however for illustrating the application of the proposed method, both cases of debris at free-surface and on-bed debris are presented (Fig. 12). 


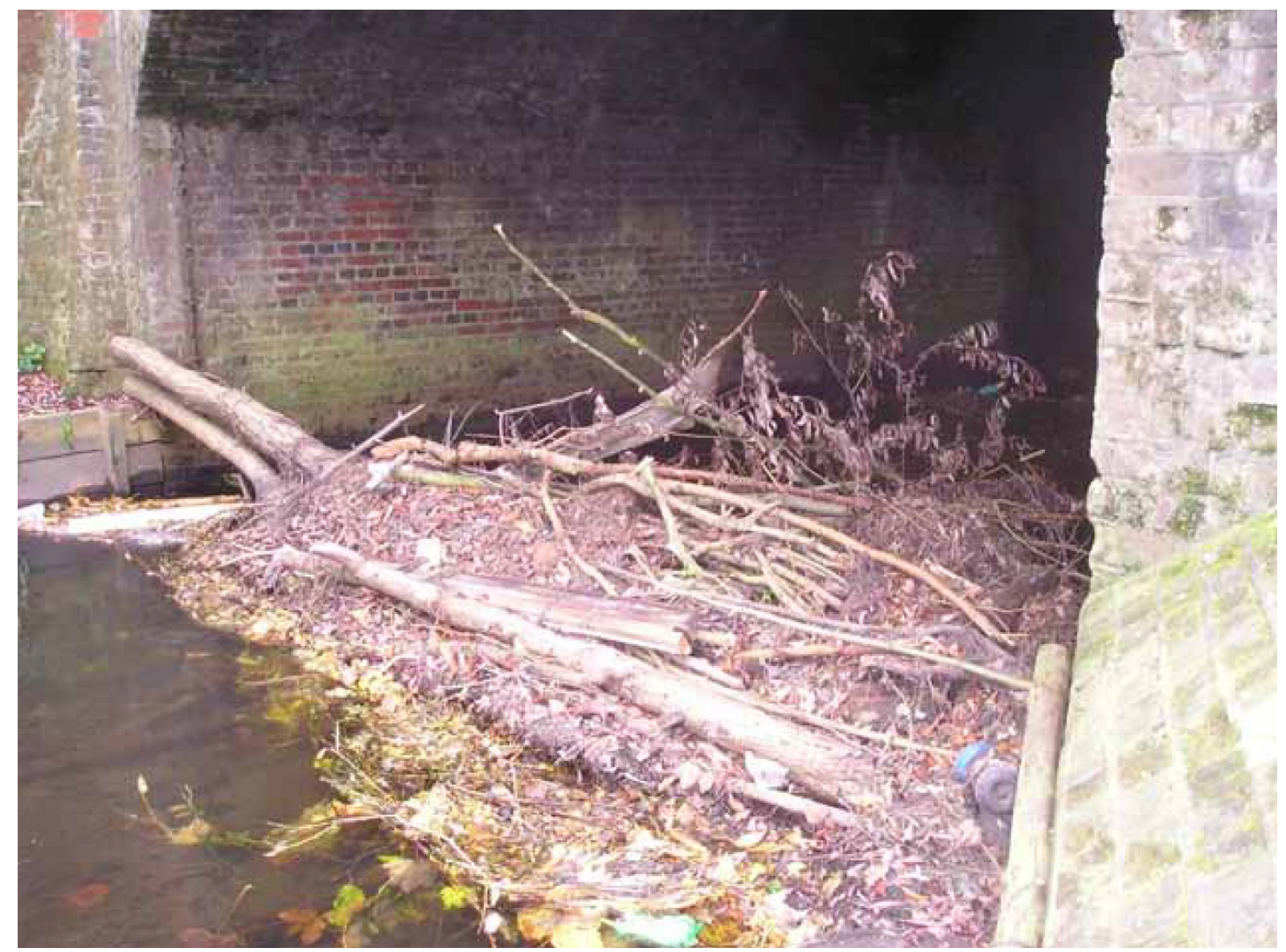

Fig. 11. Woody debris accumulation at the upstream face of Bridge RDG1 48 (looking at the east abutment). The photo is taken by Environment Agency on 28 October 2009 (RAIB 2010).

As shown in Fig. 12 for the two cases of free-surface and on-bed debris, and for $L_{d} / D=0.5, W_{d} / B=1$ and $T_{d} / h=0.5$,

$\Phi_{\text {debris }}$ is computed as 1.41 and 1.25 , respectively. These factors when multiplied with the scour depth evaluated for a scenario without debris, as obtained from available equations for estimating local scour depth, will provide the estimation of the net scour depth in the presence of debris. For example, the equation by Melville (1997) gives a local scour depth of 0.54 $\mathrm{m}$ for the east abutment. When multiplied by $\Phi_{\text {debris }}$, the new local scour depth with debris accumulation will be $0.76 \mathrm{~m}$ and $0.68 \mathrm{~m}$ for free-surface and on-bed debris, respectively. The latter scour depth is slightly greater than the foundation depth at the east (left) abutment. This shows the important effect of debris on local scour depth even when debris dimensions are underestimated. 


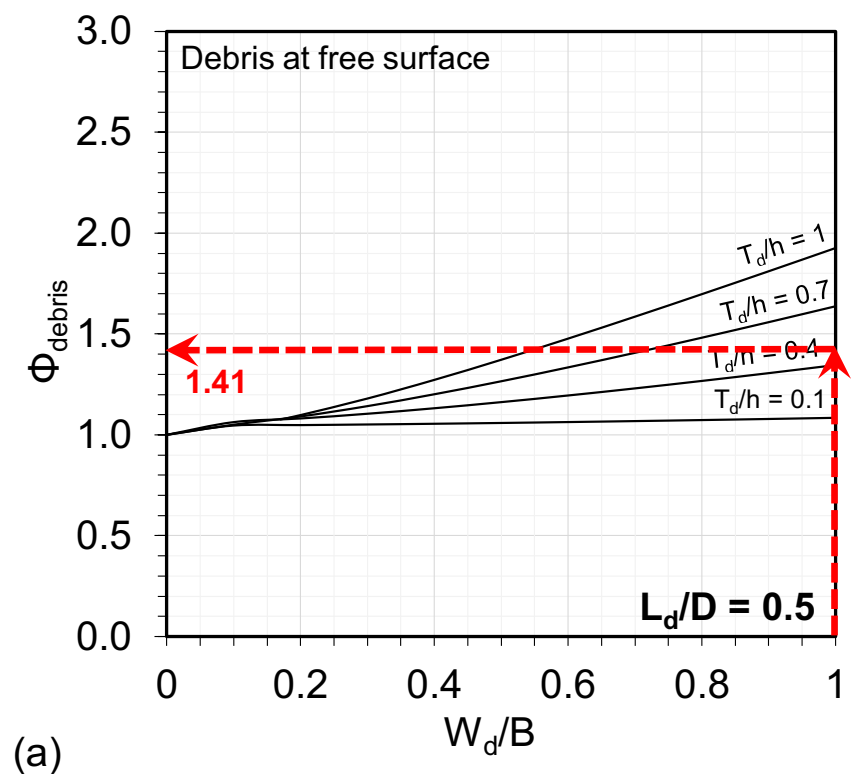

(a)

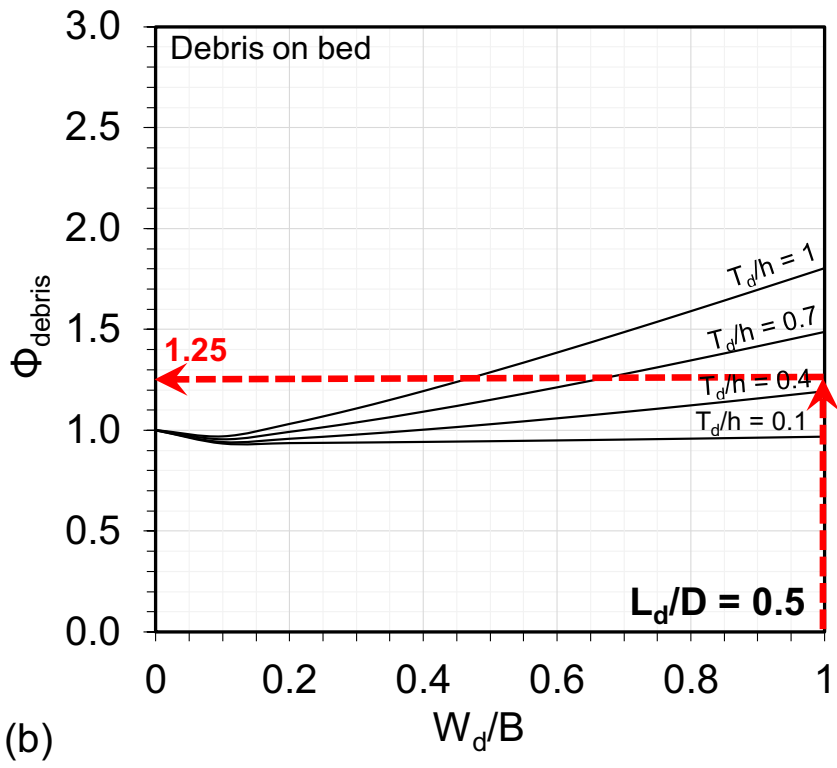

Fig. 12. Application of the proposed method to Feltham incident: (a) FS debris; (b) debris on bed.

\section{Discussion}

At the first glance the improvement of $24.6 \%$ compared to the effective pier with approach and particularly $5.6 \%$ versus the equivalent pier width approach offered by the proposed concept, as shown at the end of section "Training (Multiple Linear Regression)", may not seem substantial. However, more important than the percentile improvement is the higher reliability offered by the proposed method. As shown in Fig. 6, the predictions are uniformly distributed around the perfect-fit line, while the other two approaches have higher tendency of over prediction for higher $\Phi_{\text {debris }}$ values.

The present work is based on experimental data available from literature and has had to make reasonable assumptions to complete data sets in cases where essential data has not been provided. For example, the exact elevation of debris in water column is not given for scenarios where debris is submerged in the study by Lagasse et al. (2010). For these scenarios, the 
present study assumes that the debris centerline (depth wise) is at the mid-depth of the flow. This assumption could induce some error if debris was actually at a different elevation in the experiments. Also, various authors may have used experimental setups that have different levels of measurement error. However these errors are expected to be relatively small compared to the actual scour depths and therefore not influence the findings.

This study acknowledges that all the data used for deriving the proposed method were obtained from experiments with non-skewed flow, i.e. for flow angle of attack relative to the pier being zero. Debris may affect flow hydrodynamics in skewed flow differently and this has to be investigated further. However as the scour effect of flow angle of attack is typically incorporated directly in local scour equations, e.g. via $\Phi_{\text {angle }}$ in Eq. (1), the proposed method for evaluating $\Phi_{\text {debris }}$ is expected to give reasonable results.

As shown in section "Training (Multiple Linear Regression)", the proposed method can underestimate $d_{s} / d_{s, 0}$ albeit by a small amount in a few cases. On the other hand, the largest overestimation is related to scenarios PL004_04C, 007_01D and PL004_04A. In scenario PL004_04C, 007_01D with FS debris, measured $\Phi_{\text {debris }}$ is considerably smaller than that of test PL007_02bD with submerged debris which is unexpected. Also, test PL004_04A featured a submerged debris where debris centerline (depth wise) is assumed exactly at mid-depth of the flow. However, debris might have been closer to the bed as the measured scour depth is considerably smaller than the predicted value.

Only 4 of 43 data points in Table 1 are from experiments with debris being at the bed. These experiments were carried out with debris fixed at the bed level so that, during scour evolution, flow could be deflected by debris toward the bed. Although the bed-protecting effect of debris was obvious in these experiments, in reality debris at bed level might sink downward with scour evolution and keep protecting the bed further.

The proposed method is expected to be applicable to different pier shapes, e.g. circular, rectangular or sharp-nose piers. It is however limited to $B / h>\simeq 4.3$. The method is also developed for relative particle size of $D / d_{50} \simeq 35-145$ corresponding to non-cohesive coarse to medium sediment. Najafzadeh et al. (2016) found that $D / d_{50}$ has significant effect on scour depth with debris. Therefore, it is recommended to assess the performance of the proposed method for other range of relative particle sizes via further research.

For debris with triangular profile, it was found by Ebrahimi et al. (2018) that scour depth is $84 \%$ of non-triangular profile debris with the same thickness. Rahimi et al. (2018) found this ratio to be 74\%. Lagasse et al. (2010) found that the scour depth for wedge shape debris is $84 \%$ of that for rectangular debris with similar thickness. This is due to less severe deflection of flow toward pier base in triangular debris compared to rectangular debris (Lagasse et al. 2010 and Rahimi et al. 2018). Therefore, when triangular debris is encountered, the maximum scour depth can be evaluated by using the maximum thickness of the debris within the proposed method for computing $\Phi_{\text {debris }}$, and the resulting value multiplied by $0.74-0.84$ to obtain scour depth for triangular debris.

Although the proposed method is developed based on pier experiments, it may also be applied to bridge abutments. Results from the presented case study are reasonable; however further research may be required. 


\section{Conclusions and Recommendations}

A novel method is introduced to improve estimation of the local scour depth at bridge piers due to accumulated debris. The method computes a debris factor based on debris dimensions and elevation. Application of the novel method is illustrated for a full-scale bridge in the UK that is suspected to have failed as a result of debris-induced scour. The following are the main implications of this work.

1. The proposed method reduces the overestimation of debris-induced scour at piers prevalent in existing empirical approaches. When compared with the best estimates produced by the equivalent and effective pier width approaches of Lagasse et al. (2010) and Melville and Dongol (1992), the proposed method improves prediction accuracy by 5.6\% and $24.6 \%$, respectively. The "best" estimates of the two latter approaches is obtained with a particular local scour equation, while the proposed method can be used with any local scour equation. More importantly, the proposed method offers higher reliability and less uncertainty versus the other two approaches in estimating $\Phi_{\text {debris }}$.

2. The proposed method can be used for different debris elevations in the water column, i.e. free-surface, submerged and on-bed debris. However the most critical scenario from the perspective of scour is when debris is at free surface.

3. For the cases of debris being at free surface or at the bed with $L_{d} / D=0.5,1,2,3$ or $\geq 9$, families of charts are proposed to facilitate the application of the method. For other cases, e.g. when debris is submerged, the precise value of debris factor can be estimated from given equations.

\section{Acknowledgments}

The research presented in this paper was supported by funding from the UK's Engineering and Physical Sciences Research Council (EPSRC) under grant EP/M017354/1. The authors are grateful to all project partners for their support, particularly Devon County Council and Network Rail, for providing useful prototype data.

\section{References}

Arneson, L. A., Zevenbergen, L. W., Lagasse, P. F., and Clopper, P. E. (2012). Evaluating Scour at Bridges - Fifth Edition.

U.S. Department of Transportation, Federal Highway Administration.

Benn, J. (2013). “Railway bridge failure during flooding in the UK and Ireland.” Proceedings of the Institution of Civil

Engineers - Forensic Engineering, 166(4), 163-170.

Bradley, J., Richards, D., and Bahner, C. (2005). Debris control structures: Evaluation and countermeasures. US Dept,

Transportation. Federal Highway Administration Report No. FHWA-IF-04-016. Washington, D.C.

Chang, F. F. M., and Shen, H. W. (1979). Debris problems in the river environment. Report No. FHWA-RD-79-62. 
Chiew, Y. M. (1992). “Scour protection at bridge piers.” Journal of Hydraulic Engineering, 118(9), 1260-1269.

de Almeida, G., Cantero-Chinchilla, F. N., and Escarameia, M. (2018). "Assessing the effects of debris accumulations at river bridges. " University of Southampton.

Dias, A. J., Fael, C. S., and Núñez-González, F. (2019). “Effect of Debris on the Local Scour at Bridge Piers.” IOP Conference Series: Materials Science and Engineering, 471, 022024.

Diehl, T. (1997). Potential drift accumulation at bridges. US Department of Transportation, Federal Highway Administration, Research and Development, Turner-Fairbank Highway Research Center.

Ebrahimi, M., Kripakaran, P., Prodanović, D. M., Kahraman, R., Riella, M., Gavin, T., Arthur, S., and Djordjević, S. (2018). “Experimental Study on Scour at a Sharp-Nose Bridge Pier with Debris Blockage.” Journal of Hydraulic Engineering, 144(12), 04018071.

Jolliffe, I. (2005). “Principal Component Analysis.” Encyclopedia of Statistics in Behavioral Science, American Cancer Society.

Kirby, A., Roca, M., Kitchen, A., Escarameia, M., and Chesterton, J. (Eds.). (2015). Manual on scour at bridges and other hydraulic structures, second edition (CIRIA C742). CIRIA, London.

Lagasse, P. F., Clopper, P. E., Zevenbergen, L. W., Spitz, W. J., Girard, L. G., Ayres Associates, Inc., and Fort Collins, CO. (2010). Effects of debris on bridge pier scour. Transportation Research Board, Washington, D.C.

Laursen, E. M., and Toch, A. (1956). "Scour Around Bridge Piers and Abutments." Ames, IA: Iowa Highway Research Board.

May, R. W. P., Ackers, J. C., and Kirby, A. M. (2002). Manual on scour at bridges and other hydraulic structures (CIRIA C551). CIRIA, London.

Melville B. W. (1997). “Pier and Abutment Scour: Integrated Approach.” Journal of Hydraulic Engineering, 123(2), 125136.

Melville, B. W., and Chiew, Y. M. (1999). “Time Scale for Local Scour at Bridge Piers.” Journal of Hydraulic Engineering, 125(1), 59-65.

Melville, B. W., and Coleman, S. E. (2000). Bridge Scour. Water Resources Publication.

Melville, B. W., and Dongol, D. M. (1992). “Bridge Pier Scour with Debris Accumulation.” Journal of Hydraulic Engineering, 118(9), 1306-1310.

Melville B. W., and Sutherland A. J. (1988). “Design Method for Local Scour at Bridge Piers.” Journal of Hydraulic Engineering, 114(10), 1210-1226.

Najafzadeh, M., Rezaie Balf, M., and Rashedi, E. (2016). "Prediction of maximum scour depth around piers with debris accumulation using EPR, MT, and GEP models. ”Journal of Hydroinformatics, 18(5), 867-884.

Oliveto, G., and Hager, W. H. (2002). “Temporal Evolution of Clear-Water Pier and Abutment Scour.” Journal of Hydraulic Engineering, 128(9), 811-820. 
Pagliara, S., and Carnacina, I. (2010). “Temporal scour evolution at bridge piers: effect of wood debris roughness and porosity." Journal of Hydraulic Research, 48(1), 3-13.

Pagliara, S., and Carnacina, I. (2011a). “Influence of Wood Debris Accumulation on Bridge Pier Scour.” Journal of Hydraulic Engineering, 137(2), 254-261.

Pagliara, S., and Carnacina, I. (2011b). “Influence of large woody debris on sediment scour at bridge piers.” International Journal of Sediment Research, 26(2), 121-136.

Parola, A. C., Apelt, C. J., and Jempson, M. A. (2000). Debris forces on highway bridges. NCHRP report, National Academy Press, Washington, D.C.

Rahimi, E., Qaderi, K., Rahimpour, M., and Ahmadi, M. M. (2018). “Effect of Debris on Piers Group Scour: An Experimental Study. ” KSCE Journal of Civil Engineering, 22(4), 1496-1505.

RAIB (Rail Accident Investigation Branch). (2010). Failure of Bridge RDG1 48 (River Crane) between Whitton and Feltham 14 November 2009. Department for Transport, U.K.

Richardson, E. V., and Davies, S. R. (2001). Evaluating Scour at Bridges. Fourth edition. Federal Highway Administration Report, Springfield, V.A.

Rosgen, D. L. (1985). “A stream classification system.” Riparian ecosystems and their management: First North American Riparian Conference. Rocky Mountain Forest and Range Experiment Station, 5.

Sheppard, D. M., Melville, B. W., and Demir. (2014). "Evaluation of Existing Equations for Local Scour at Bridge Piers." Journal of Hydraulic Engineering, 140(1), 14-23.

Wellwood, N., and Fenwick, J. (1990). “A flood loading methodology for bridges.” Australian Road Research Board (ARRB) Conference, 15th, 1990, Darwin, Northern Territory. 
Table 1. Experimental data used to derive debris factor

\begin{tabular}{|c|c|c|c|c|c|c|c|c|c|c|c|c|c|c|c|}
\hline Test & Group & Debris shape & $B(\mathrm{~m})$ & $h(\mathrm{~m})$ & $U(\mathrm{~m} / \mathrm{s})$ & $U / U_{c r}$ & $D(\mathrm{~m})$ & $d_{50}(\mathrm{~mm})$ & Duration (hr) & $L_{d}(\mathrm{~m})$ & $W_{d}(\mathrm{~m})$ & $T_{d}(\mathrm{~m})$ & Debris elevation & $h_{d}(\mathrm{~m})$ & $d_{s} / d_{s, 0}$ \\
\hline ME2 & 1 & Log shape & 0.605 & 0.08 & 0.395 & 0.94 & 0.05 & 1.37 & 5 & 0.016 & 0.3 & 0.016 & At FS & 0.064 & 1.14 \\
\hline ME9 & 1 & Log shape & 0.605 & 0.08 & 0.395 & 0.94 & 0.05 & 1.37 & 5 & 0.032 & 0.3 & 0.032 & At FS & 0.048 & 1.33 \\
\hline ME12 & 1 & Log shape & 0.605 & 0.131 & 0.421 & 0.94 & 0.05 & 1.37 & 5 & 0.032 & 0.3 & 0.032 & At FS & 0.099 & 1.29 \\
\hline ME3 & 1 & Log shape & 0.605 & 0.08 & 0.395 & 0.94 & 0.05 & 1.37 & 5 & 0.016 & 0.3 & 0.016 & Submerged & 0.044 & 1.06 \\
\hline ME4 & 1 & Log shape & 0.605 & 0.08 & 0.395 & 0.94 & 0.05 & 1.37 & 5 & 0.016 & 0.3 & 0.016 & Submerged & 0.021 & 1.01 \\
\hline ME10 & 1 & Log shape & 0.605 & 0.08 & 0.395 & 0.94 & 0.05 & 1.37 & 5 & 0.032 & 0.3 & 0.032 & On bed & 0 & 1.07 \\
\hline ME8 & 1 & Rectangular & 0.605 & 0.08 & 0.395 & 0.94 & 0.05 & 1.37 & 5 & 0.15 & 0.3 & 0.016 & On bed & 0 & 0.62 \\
\hline ME5 & 1 & Log shape & 0.605 & 0.08 & 0.395 & 0.94 & 0.05 & 1.37 & 5 & 0.016 & 0.3 & 0.016 & On bed & 0 & 0.88 \\
\hline ME13 & 1 & Log shape & 0.605 & 0.131 & 0.421 & 0.94 & 0.05 & 1.37 & 5 & 0.032 & 0.3 & 0.032 & On bed & 0 & 0.94 \\
\hline PL005_02B, $006 \_01 \mathrm{~B}, 009 \_02 \mathrm{C}, 006 \_02 \mathrm{~B}$ & 2 & Rectangular & 2.438 & 0.305 & 0.427 & 1 & 0.102 & 0.7 & 8 & 0.305 & 0.610 & 0.101 & At FS & 0.204 & 1.27 \\
\hline PL006_02A, 005_02A, 006_01A & 2 & Rectangular & 2.438 & 0.305 & 0.427 & 1 & 0.102 & 0.7 & 8 & 0.305 & 0.610 & 0.204 & At FS & 0.101 & 1.46 \\
\hline PL004_03A & 2 & Rectangular & 2.438 & 0.305 & 0.427 & 1 & 0.102 & 0.7 & 8 & 0.610 & 0.610 & 0.101 & Submerged & 0.102 & 0.94 \\
\hline PL004_04A & 2 & Rectangular & 2.438 & 0.305 & 0.427 & 0.7 & 0.102 & 0.7 & 8 & 0.610 & 0.610 & 0.101 & Submerged & 0.102 & 0.82 \\
\hline PL009_01A, 009_02A & 2 & Rectangular & 2.438 & 0.305 & 0.427 & 1 & 0.102 & 0.7 & 8 & 0.610 & 0.610 & 0.101 & At FS & 0.204 & 1.11 \\
\hline PL004_03B & 2 & Rectangular & 2.438 & 0.305 & 0.427 & 1 & 0.102 & 0.7 & 8 & 0.610 & 0.610 & 0.204 & At FS & 0.101 & 1.10 \\
\hline PL007_02bD & 2 & Rectangular & 2.438 & 0.305 & 0.427 & 0.7 & 0.102 & 0.7 & 8 & 0.914 & 1.219 & 0.204 & Submerged & 0.050 & 1.31 \\
\hline PL004_04C, 007 01D & 2 & Rectangular & 2.438 & 0.305 & 0.427 & 1 & 0.102 & 0.7 & 8 & 0.914 & 1.219 & 0.204 & At FS & 0.101 & 1.14 \\
\hline PL004_04D, 009_02D & 2 & Rectangular & 2.438 & 0.305 & 0.427 & 1 & 0.102 & 0.7 & 8 & 1.219 & 1.829 & 0.204 & At FS & 0.101 & 1.42 \\
\hline PL004_03C & 2 & Rectangular & 2.438 & 0.305 & 0.427 & 1 & 0.102 & 0.7 & 8 & 0.914 & 1.219 & 0.204 & At FS & 0.101 & 1.34 \\
\hline PL004_03D & 2 & Rectangular & 2.438 & 0.305 & 0.427 & 0.7 & 0.102 & 0.7 & 8 & 1.219 & 1.829 & 0.204 & At FS & 0.101 & 1.59 \\
\hline BM1 & 3 & Semi-circular ${ }^{a}$ & 1.52 & 0.35 & 0.65 & 1 & 0.058 & 1.65 & 150 & 0.09 & 0.18 & 0.03 & At FS & 0.32 & 1.05 \\
\hline BM2 & 3 & Semi-circular & 1.52 & 0.35 & 0.65 & 1 & 0.058 & 1.65 & 150 & 0.09 & 0.18 & 0.063 & At FS & 0.287 & 1.08 \\
\hline BM3 & 3 & Semi-circular & 1.52 & 0.35 & 0.65 & 1 & 0.058 & 1.65 & 150 & 0.09 & 0.18 & 0.095 & At FS & 0.255 & 1.13 \\
\hline BM4 & 3 & Semi-circular & 1.52 & 0.35 & 0.65 & 1 & 0.058 & 1.65 & 150 & 0.09 & 0.18 & 0.195 & At FS & 0.155 & 1.20 \\
\hline BM5 & 3 & Semi-circular & 1.52 & 0.25 & 0.62 & 1 & 0.058 & 1.65 & 150 & 0.09 & 0.18 & 0.03 & At FS & 0.22 & 1.11 \\
\hline BM6 & 3 & Semi-circular & 1.52 & 0.25 & 0.62 & 1 & 0.058 & 1.65 & 150 & 0.09 & 0.18 & 0.063 & At FS & 0.187 & 1.14 \\
\hline BM7 & 3 & Semi-circular & 1.52 & 0.25 & 0.62 & 1 & 0.058 & 1.65 & 150 & 0.09 & 0.18 & 0.095 & At FS & 0.155 & 1.18 \\
\hline BM8 & 3 & Semi-circular & 1.52 & 0.25 & 0.62 & 1 & 0.058 & 1.65 & 150 & 0.09 & 0.18 & 0.195 & At FS & 0.055 & 1.25 \\
\hline BM9 & 3 & Semi-circular & 1.52 & 0.15 & 0.58 & 1 & 0.058 & 1.65 & 150 & 0.09 & 0.18 & 0.03 & At FS & 0.12 & 1.14 \\
\hline BM10 & 3 & Semi-circular & 1.52 & 0.15 & 0.58 & 1 & 0.058 & 1.65 & 150 & 0.09 & 0.18 & 0.063 & At FS & 0.087 & 1.16 \\
\hline BM11 & 3 & Semi-circular & 1.52 & 0.15 & 0.58 & 1 & 0.058 & 1.65 & 150 & 0.09 & 0.18 & 0.095 & At FS & 0.055 & 1.15 \\
\hline BM12 & 3 & Semi-circular & 1.52 & 0.1 & 0.54 & 1 & 0.058 & 1.65 & 150 & 0.09 & 0.18 & 0.03 & At FS & 0.07 & 1.14 \\
\hline BM13 & 3 & Semi-circular & 1.52 & 0.1 & 0.54 & 1 & 0.058 & 1.65 & 150 & 0.09 & 0.18 & 0.063 & At FS & 0.037 & 1.26 \\
\hline BM14 & 3 & Semi-circular & 1.52 & 0.1 & 0.54 & 1 & 0.058 & 1.65 & 150 & 0.09 & 0.18 & 0.095 & At FS & 0.005 & 1.20 \\
\hline BM15 & 3 & Semi-circular & 1.52 & 0.35 & 0.65 & 1 & 0.058 & 1.65 & 150 & 0.06 & 0.12 & 0.095 & At FS & 0.255 & 1.10 \\
\hline BM16 & 3 & Semi-circular & 1.52 & 0.25 & 0.62 & 1 & 0.058 & 1.65 & 150 & 0.06 & 0.12 & 0.095 & At FS & 0.155 & 1.11 \\
\hline BM17 & 3 & Semi-circular & 1.52 & 0.15 & 0.58 & 1 & 0.058 & 1.65 & 150 & 0.05 & 0.12 & 0.095 & At FS & 0.055 & 1.09 \\
\hline BM18 & 3 & Semi-circular & 1.52 & 0.35 & 0.65 & 1 & 0.058 & 1.65 & 150 & 0.2 & 0.4 & 0.095 & At FS & 0.255 & 1.29 \\
\hline BM19 & 3 & Semi-circular & 1.52 & 0.25 & 0.62 & 1 & 0.058 & 1.65 & 150 & 0.2 & 0.4 & 0.095 & At FS & 0.155 & 1.42 \\
\hline BM20 & 3 & Semi-circular & 1.52 & 0.15 & 0.58 & 1 & 0.058 & 1.65 & 150 & 0.2 & 0.4 & 0.095 & At FS & 0.055 & 1.25 \\
\hline BM21 & 3 & Semi-circular & 1.52 & 0.3 & 0.64 & 1 & 0.058 & 1.65 & 150 & 0.2 & 0.4 & 0.195 & At FS & 0.105 & 1.38 \\
\hline BM22 & 3 & Semi-circular & 1.52 & 0.2 & 0.6 & 1 & 0.058 & 1.65 & 150 & 0.2 & 0.4 & 0.195 & At FS & 0.005 & 1.49 \\
\hline BM23 & 3 & Semi-circular & 1.52 & 0.1 & 0.54 & 1 & 0.058 & 1.65 & 150 & 0.2 & 0.4 & 0.1 & At FS & 0 & 1.26 \\
\hline
\end{tabular}

Corresponding to the debris portion located upstream the pier center 
